\title{
Neurological Involvement in Children with Hemolytic Uremic Syndrome
}

Caoimhe Suzanne Costigan ( $\nabla$ costigcs@tcd.ie)

Children's Health Ireland at Temple Street https://orcid.org/0000-0002-0091-0712

Tara Raftery

Children's Health Ireland at Temple Street

Anne G Carroll

Children's Health Ireland at Temple Street

Dermot Wildes

Children's Health Ireland at Temple Street

Claire Reynolds

Children's Health Ireland at Temple Street

Robert Cunney

Children's Health Ireland at Temple Street

Niamh Dolan

Children's Health Ireland at Temple Street

Richard J Drew

Children's Health Ireland at Temple Street

Bryan J Lynch

Children's Health Ireland at Temple Street

Declan J O'Rourke

Children's Health Ireland at Temple Street

Maria Stack

Children's Health Ireland at Temple Street

Clodagh Sweeney

Children's Health Ireland at Temple Street

Amre Shahwan

Children's Health Ireland at Temple Street

Eilish Twomey

Children's Health Ireland at Temple Street

Mary Waldron

Children's Health Ireland at Crumlin

Michael Riordan

Children's Health Ireland at Temple Street 
Children's Health Ireland at Temple Street

Kathleen Gorman ( $\square$ kathleen.gorman@cuh.ie )

Children's Health Ireland at Temple Street

\section{Research Article}

Keywords: HUS, STEC-HUS, neurology, neurological involvement

Posted Date: June 7th, 2021

DOl: https://doi.org/10.21203/rs.3.rs-430283/v1

License: (c) (i) This work is licensed under a Creative Commons Attribution 4.0 International License. Read Full License

Version of Record: A version of this preprint was published at European Journal of Pediatrics on August 10th, 2021. See the published version at https://doi.org/10.1007/s00431-021-04200-1. 


\section{Abstract}

Our objective was to establish the rate of neurological involvement in STEC-HUS and describe the clinical presentation, management and outcome. A retrospective chart review of children aged $\leq 16$ years with STEC-HUS in Children's Health Ireland from 2005 to 2018 was conducted. Laboratory confirmation of STEC infection was required for inclusion. Neurological involvement was defined as encephalopathy, focal neurological deficit and/or seizure activity. Data on clinical presentation, management and outcome were collected. We identified 240 children with HUS; 202 had confirmed STEC infection. Neurological involvement occurred in $22(10.9 \%)$. The most common presentation was seizures $(72.7 \%)$. In the neurological group, 19 (86.4\%) were treated with plasma exchange and/or Eculizumab. Of the 21 surviving children with neurological involvement, 19 (90.5\%) achieved a complete neurological recovery. A higher proportion of children in the neurological group had renal sequelae $(26.6 \%$ vs. $11.5 \%, P=.031)$. One patient died from multi-organ failure. Conclusion: We have identified the rate of neurological involvement in a large cohort of children with STEC-HUS as $10.9 \%$. Neurological involvement in STECHUS is associated with good long-term outcome (complete neurological recovery in $90.5 \%$ ) and a low case-fatality rate $(4.5 \%)$ in our cohort.

\section{Introduction}

Hemolytic uremic syndrome (HUS) is characterized by a triad of thrombocytopenia, microangiopathic hemolytic anemia and kidney failure. Shiga toxin-producing Escherichia coli (STEC)-HUS is typically preceded by a diarrheal illness (usually bloody). In Ireland, the most common Escherichia coli (E. coli) serotype is 0157:H7.[1] Shiga toxin induces an inflammatory cascade, triggering endothelial injury, and thrombotic microangiopathy; resulting in micro-thrombi formation in multiple organs.[2-4] Activation of the alternative complement pathway may also have a role.[5] Shiga toxin-producing E. coli HUS is the most common cause of acute kidney injury in children.[1, 6-9] Since 2004, STEC is a notifiable disease in Ireland and we consistently have the highest reported rate of STEC infection in Europe (19.4 per 100,000 in 2017).[10]

Neurological involvement is reported in approximately $30 \%$ of all types of HUS. [2, 11-29] Seizures, irritability, lethargy, encephalopathy and coma are the most common central nervous system (CNS) manifestations. Neurological involvement in STEC-HUS is associated with a higher mortality rate (up to $30 \%$ ), long-term physical disability, neuropsychological and cognitive sequelae (Supplementary Table 1). $[11-16,18,21-25,27-35]$

Shiga toxin-producing Escherichia coli HUS is managed with careful fluid and diuretic administration, red cell transfusion and in up to $50 \%$ of cases temporary kidney replacement therapy [continuous venovenous hemofiltration (CVVH), peritoneal dialysis (PD) or hemodialysis (HD)].[36] There is no consensus on the treatment of CNS involvement in STEC-HUS. Mixed outcomes have been reported after treatment with plasma exchange (PE) and/or anti-C5 monoclonal antibodies e.g. Eculizumab.[13, 29, 34, 37-43] 
We have reviewed all cases of STEC- HUS in children ( $\leq 16$ years) referred to tertiary pediatric nephrology services in the Republic of Ireland over 13 years $(n=202)$. We report the rate of neurological involvement in this group; describe the clinical presentation, neurological and renal outcomes, and present an overview of management.

\section{Methods}

\section{Study Design}

We undertook a retrospective chart review of children aged $\leq 16$ years with STEC-HUS in Children's Health Ireland, Dublin from, January $1^{\text {st }}, 2005$, to December $31^{\text {st }}, 2018$. Children's Health Ireland is the sole provider of tertiary pediatric nephrology services in the Republic of Ireland. Patients were identified through the hospital discharge coding system and the nephrology patient database.

\section{STEC-HUS Case Definition}

Hemolytic uremic syndrome was defined as acute kidney injury, microangiopathic hemolytic anemia and thrombocytopenia. Laboratory confirmation of STEC was performed at the Health Service Executive Public Health Laboratory at Cherry Orchard Hospital, Dublin, which provides the National Reference service for STEC. Criteria for microbiological confirmation (as per national Health Surveillance and Protection Centre criteria) was: (1) isolation of an E. coli strain by culture that is known to produce Shiga toxin (stx) or harbours $s t x 1$ or stx 2 gene(s), or (2) direct detection of $s t x 1$ or $s t x 2$ nucleic acid (without strain isolation) by polymerase chain reaction (PCR), or (3) detection of $E$. coli serogroup specific antibodies.[10]

\section{Neurological Manifestations}

Neurological involvement was defined as encephalopathy (altered or fluctuating level of consciousness), focal neurological deficit (abnormal neurological examination) and/or seizure activity. Patients were divided into those with neurological involvement (neurological group) and those without (nonneurological group). The total group refers to all children with STEC-HUS. Image interpretation was performed by two specialized pediatric radiologists.

\section{Exclusion Criteria}

Children with HUS who did not have confirmed STEC infection or had proven STEC infection but had a confirmed genetic diagnosis of atypical-HUS (aHUS) were excluded (Supplementary Figure 1).

\section{Outcome}


Renal sequelae were defined as the presence of one of the following: (1) hypertension requiring antihypertensive medication; (2) proteinuria ( $>0.15 \mathrm{~g} / \mathrm{L}$ or urinary protein-to-creatinine ratio greater than $20 \mathrm{mg} / \mathrm{mmol}$ ); (3) impaired kidney function with an estimated glomerular filtration rate $<90 \mathrm{~mL} / \mathrm{min} /$ $1.73 \mathrm{~m}^{2}$ (Pediatric Schwartz formula).[44] Neurological sequelae were defined as recurrent seizures, focal neurological deficit or altered functional status at follow-up. The Pediatric Cerebral Performance Category (PCPC) was used as a qualitative assessment of overall neurological morbidity.[45]

\section{Ethical approval}

Ethical approval was granted by the local research and ethic committee.

\section{Statistical analysis}

Data was analyzed using the SPSS version 26.0 (IBM SPSS Statistics, IBM Corporation). Data was assessed for normality. Parametric data were analyzed by 2-tailed, non-paired $t$-tests. Mann-Whitney Utest and chi square test analyzed non-parametric data. Quantitative variables were expressed as median (IQR). Statistical significance was determined at $P$-value less than .05.

\section{Results}

\section{Population}

We identified 240 children with HUS. No evidence of STEC infection was detected in $36 / 240$ (15\%) patients. Two children had confirmed STEC infection but later developed recurrence of HUS in the absence of STEC infection - pathogenic complement gene mutations were subsequently identified. Two hundred and two children with confirmed STEC infection (total group) were included in the analysis (Supplementary Figure 1). Neurological involvement was identified in 22/202 children (10.9\%) (Table 1).

\section{Microbiology}

A Shiga toxigenic strain of E. coli was isolated in 187/202 (92\%) children on stool culture; 172 also had stx detected on PCR and 37 had antibodies on serology. Seven E. coli serotypes were identified; 0157 $(50 \%)$ and $026(30 \%)$ were the most common. Sixteen patients $(8 \%)$ had an ungroupable E. coli serotype (Table 2). In 4 patients, stx was detected without isolation of an E. coli strain. Both stx 1 and stx 2 were detected in 43 children, stx 2 alone in 109 and stx 1 alone in three. Unspecified stx was identified in 18 and no stx detected in 27.

\section{Clinical Presentation}

At presentation, 196/202 (97.0\%) children had diarrhea, of whom 121/196 (61\%) had bloody diarrhea, and 45/202 (22\%) were febrile. There was a significantly higher proportion of patients in the neurological 
group with oliguria or anuria [95.5\% vs. $75.6 \%(P=.034)]$. The degree of leukocytosis, thrombocytopenia, anemia and hyponatremia at presentation were not significantly different between groups. Admission and peak creatinine were similar in both groups (Table 1). Admission rate to the PICU was higher [86.4\% vs. $16.1 \%(P<.001)]$ and median length of hospital stay was longer [ 21.0 days vs. 9.0 days $(P<.001)]$ in the neurological group.

\section{Neurological Presentation}

The neurological group comprised of 22 children (Table 3 ). The median time from admission to the onset of CNS symptoms (seizures, encephalopathy or focal neurological impairment) was one day (IQR: 0.0-2.3 days). Seizure was the most common presentation [16/22 (72.7\%)]; four children presented with status epilepticus. Ten patients were clinically encephalopathic, and four had focal neurological deficits. Antiepileptic medications were used during hospital admission in 16 patients; four remained on medication at discharge. All medications had been discontinued by six months post-discharge.

Electroencephalogram was performed in 10 children during the acute illness. All studies were abnormal, with a slow background consistent with encephalopathy in nine and absent cerebral activity in one.

Neuroimaging was available in 17 children (Table 3). Ten patients had no acute findings on neuroimaging despite clinical evidence of encephalopathy [3 magnetic resonance imaging (MRI); 4 computer tomography (CT); 3 both MRI \& CT]. There was no difference in the timing of imaging between those with or without acute changes. Table $\mathbf{3}$ summarizes neuroimaging findings. Figure 1 illustrates the typical restricted diffusion pattern on diffusion-weighted imaging (DWI). Three patients had follow-up MRI studies which showed improvement or complete resolution.

\section{Management}

In the total group, 107/202 (53\%) required dialysis. Significantly more patients in the neurological group needed dialysis than in the non-neurological group [86.4\% vs. $48.9 \%,(P<.001)]$. The most common modality utilized was PD in 83/107 (77\%); CVVH in 16 and 8 children had both.

In the total group, 24/202 (11.9\%) had PE; 15/22 (68.2\%) in the neurological group and 9/180 (5.0\%) in the non-neurological group. The median number of PE sessions in the neurological group was 4.0 (IQR: 3.0-5.0). Patients who received PE without evidence of CNS involvement ( $n=9)$ did so due to atypical presentation before the confirmation of STEC. Eight children had Eculizumab, all in the neurological group (Supplementary Figure 1).

In the neurological group, 19/22 patients (86.4\%) had either PE or Eculizumab (Table 3). Three patients received neither - one had a single seizure in a referring hospital but was not clinically encephalopathic on arrival at our center (Patient 4); one had a prolonged PICU admission and neurological deficits were only noted post-extubation (Patient 19); one had a seizure felt to be related to severe hypertension at the time (Patient 22). One patient received Eculizumab then PE (four days later) due to the re-emergence of neurological signs (abnormal neurological examination, increased tone and altered level of 
consciousness) despite an initial improvement (Patient 16). Three received PE then Eculizumab - due to concerns regarding response to the initial treatment or evolving diagnostic uncertainty. Plasma exchange was commenced within 24 hours of the onset of neurological symptoms in 13 of 15 (86.6\%) cases. Four patients were treated with Eculizumab alone. All patients who received Eculizumab initially did so within 24 hours.

One patient in the neurological group died from multi-organ failure. Two patients developed central line related deep venous thrombosis requiring anticoagulation. One of these patients also received treatment for an associated fungal infection. All patients who got Eculizumab, were given antibiotic prophylaxis and appropriate meningococcal vaccination.

\section{Outcomes}

Neurological

Of the 21 surviving patients with neurological involvement, 19/21 (90.5\%) made a complete recovery. Two patients (9.5\%) had mild impairment on PCPC at both discharge and most recent follow-up: both reported difficulties with complex motor tasks. One patient developed a brief generalized onset-motor seizure one-year post-discharge but was not commenced on anti-epileptic medication.

Renal

Complete follow-up data was available on 178/202 children (88.1\%), 18 (8.9\%) were referred to regional pediatric centers for follow-up and $5(2.5 \%)$ were lost to follow-up. Renal recovery was achieved in 154/178 (86.5\%) after a median follow-up of 2.4 years (IQR: 0.7-5.5 years). A greater proportion of patients in the neurological group had renal sequelae ( $26.6 \%$ vs. $11.5 \% ; P=.031)$ (Table 4). Two patients, one from each group, developed stage 5 chronic kidney disease and were transplanted.

\section{Discussion}

We have identified that the rate of neurological involvement in STEC-HUS is $10.9 \%$. Neurological involvement is associated with predominantly good long-term outcome $(90.4 \%)$ and a reduced casefatality rate (4.5\%) compared to older reports.

The reported rate of neurological involvement in children with HUS varies between $10.4 \%$ and $52 \%$ (Supplementary Table 1).[11-16, 18, 20-25, 27-35] We report a rate of $10.9 \%$ based on a strict definition of neurological involvement (seizures, encephalopathy or focal neurological deficit). We considered features such as irritability or lethargy to be non-specific. Four patients met the criteria for neurological involvement, but STEC infection was not confirmed, and they were excluded; no alternative etiology was identified. The possibility of failure to identify STEC infection in this small group exists - their inclusion would increase the rate of neurological involvement to $12.3 \%$. 
Seizure [16/22 (72.7\%)] was the most common presentation of neurological involvement. Neurological involvement was noted early in the disease course, manifesting within 48 hours of admission to hospital in $72.7 \%$. Close monitoring of CNS symptoms and careful clinical assessment is important to identify neurological involvement in children with HUS early in the course of their disease.

Demographic variables did not predict neurological involvement in our cohort and we did not identify a trend for a higher degree of leukocytosis or peak creatinine, as reported previously (Table 1).[14, 18, 46] The E. coli serogroups identified were comparable between the neurological and non-neurological groups. Children in the neurological group had a significantly greater need for dialysis [86.4\% vs. $48.9 \%,(P<.001)]$, PICU admission [86.4\% vs. $16.1 \%,(p<0.001)]$ and a longer length of hospital stay [21(13-34) vs. $9(6-15)$, $(p<0.001)]$, reflecting a more severe course of illness in this group.

Neuro-radiology in children with HUS is focused on the exclusion of hemorrhage and the identification of cerebral edema and vasculitis.[19] Children in the neurological group underwent CT and/or MRI depending on their individual clinical circumstances. Based on availability, and if patients are sufficiently stable to allow for a longer examination duration, MRI is the imaging modality of choice. We identified the typical DWI abnormalities of both deep white and grey matter in our patients $(n=7)$. [13] All children who had DWI changes had a normal neurological outcome (Table 3). Therefore, observed DWI changes are reversible lesions in children with good neurological recovery and routine follow up neuroimaging is not required, unless abnormal neurological examination.

Evidence supporting the use of supplemental treatments, such as PE or Eculizumab, in STEC-HUS is lacking.[47-50] Extensive cases series and small cohort studies have been published but no randomized control trials have been reported (Supplementary Table 2). [13, 15, 29, 33, 34, 37-43, 51-53] Many specialists, whilst cautiously skeptical of the role of such treatments, tend to use supplemental therapies in severe cases of HUS, particularly in the context of CNS involvement.[47-50] In our cohort, we reserved additional treatments for children with severe disease, treating 20/202 children (9.9\%) with PE, 4/202 (1.9\%) with Eculizumab and 4/202 (1.9\%) with both. Our initial approach is treatment with PE; reserving Eculizumab for use when prompt initiation of PE is not practicable or if overwhelming multi-system involvement. It is important to avoid the simultaneous use of PE and Eculizumab as monoclonal antibodies will be removed by PE. It is difficult, based on our positive experience, to forgo supplemental therapies until the outcomes of randomized controlled trials are available.

Neurological involvement in HUS has been reported to be associated with high mortality and significant long-term neurological morbidity (Supplementary Table 1).[11-16, 18, 20-25, 27-35] Reported outcomes vary depending on the period studied and the case definition employed. Studies based on cohorts of children with HUS and CNS involvement before 2010 had a median mortality rate of $16.9 \%$ (IQR: 7.0-44.6\%)[11, 12, 19, 21-25, 27, 28, 30] and long-term neurological sequelae of 13.8\% (IQR: 11.133.2\%).[12, 19, 22, 24, 30,31] More recent studies (cohorts after 2010), have better outcomes with lower mortality [13.9\%, (IQR:12.5-22\%)][13, 14, 16, 18, 20,34] and less long-term neurological sequelae [8.3\%, IQR: $5.3-34.6 \%)] .[13,15,16,18,33-35]$ Substantial improvements in diagnosis and supportive care have 
evolved in the intervening period. In our neurological group $(n=22)$, one patient died, and two children had long-term neurological consequences - giving comparative rates of $4.5 \%$ case-fatality, $9.5 \%$ mild neurological sequelae and no severe neurological sequelae. The rate of kidney sequelae on follow-up is significantly better than that described in other cohorts $-13.5 \%$ vs $20-25 \%$. $[2,54]$ It is likely that advances in supportive care are the primary driver for improved outcomes (renal and neurological) in our cohort compared to older published cohorts. We believe that more optimism should be afforded when counseling parents regarding long-term neurological and renal sequelae.

Making comparisons between cohorts of HUS patients treated using different protocols in different centers is not optimal. Differences in the case definition, case capture, inclusion of aHUS patients, length of follow-up and treatment modalities, along with demographic variables and the genetic background of the population make comparisons complex. Our cohort benefits from a high degree of case capture based on a well-defined geographical area served by a single tertiary center -near complete capture of HUS cases with more mild disease involvement will have an impact on measurement of overall disease severity.

One important limitation of our study is the ability to detect more subtle changes in neurocognitive function and behavior. The PCPC was developed to quantify overall functional morbidity in children after critical illness- application of more sensitive scales may allow for the detection of more subtle changes in neurocognitive outcomes and behavior.[46, 55, 56]

\section{Conclusion}

One in ten children with STEC-HUS will have neurological involvement and $90 \%$ will have a complete neurological recovery. The optimal management of neurological involvement in STEC-HUS needs further study. In the absence of good quality randomized control studies, it is important that cohort studies are reported.

\section{References}

1. Tarr PI, Gordon CA, Chandler WL (2005) Shiga-toxin-producing Escherichia coli and haemolytic uraemic syndrome. Lancet 365:1073-1086. https://doi.org/10.1016/S0140-6736(05)71144-2

2. Trachtman H, Austin C, Lewinski M, Stahl RAK (2012) Renal and neurological involvement in typical Shiga toxin-associated HUS. Nat Rev Nephrol 8:658-669. https://doi.org/10.1038/nrneph.2012.196

3. Gallo GE, Gianantonio CA (1995) Extrarenal involvement in diarrhoea-associated haemolytic-uraemic syndrome. Pediatr Nephrol 9:117-119. https://doi.org/10.1007/BF00858990

4. Mayer CL, Leibowitz CS, Kurosawa S, Stearns-Kurosawa DJ (2012) Shiga toxins and the pathophysiology of hemolytic uremic syndrome in humans and animals. Toxins (Basel). 4:12611287 
5. Orth D, Khan AB, Naim A, et al (2009) Shiga Toxin Activates Complement and Binds Factor H: Evidence for an Active Role of Complement in Hemolytic Uremic Syndrome. J Immunol 182:63946400. https://doi.org/10.4049/jimmunol.0900151

6. Lynn RM, O'Brien SJ, Taylor CM, et al (2005) Childhood hemolytic uremic syndrome, United Kingdom and Ireland. Emerg Infect Dis 11:590-596. https://doi.org/10.3201/eid1104.040833

7. Jacquinet S, De Rauw K, Pierard D, et al (2018) Haemolytic uremic syndrome surveillance in children less than 15years in Belgium, 2009-2015. Arch Public Heal 76:. https://doi.org/10.1186/s13690-0180289-x

8. Rowe PC, Walop W, Lior H, Mackenzie AM (1991) Haemolytic anaemia after childhood Escherichia coli 0 157.H7 infection: Are females at increased risk? Epidemiol Infect 106:523-530. https://doi.org/10.1017/S0950268800067583

9. Jenssen GR, Hovland E, Bjerre A, et al (2014) Incidence and etiology of hemolytic-uremic syndrome in children in Norway, 1999-2008 - a retrospective study of hospital records to assess the sensitivity of surveillance. BMC Infect Dis 14:1-9. https://doi.org/10.1186/1471-2334-14-265

10. HSE Health Protection Surveillance Centre. VTEC Infection in Ireland, 2017. Dublin: HSE HPSC; 2019

11. ROONEY JC, ANDERSON RM, HOPKINS IJ (1971) CLINICAL AND PATHOLOGICAL ASPECTS OF CENTRAL NERVOUS SYSTEM INVOLVEMENT IN THE HAEMOLYTIC URAEMIC SYNDROME. J Paediatr Child Health 7:28-33. https://doi.org/10.1111/j.1440-1754.1971.tb02465.x

12. Rosales A, Hofer J, Zimmerhackl L-B, et al (2012) Need for Long-term Follow-up in Enterohemorrhagic Escherichia coli-Associated Hemolytic Uremic Syndrome Due to Late-Emerging Sequelae. Clin Infect Dis 54:1413-1421. https://doi.org/10.1093/cid/cis196

13. Gitiaux C, Krug P, Grevent D, et al (2013) Brain magnetic resonance imaging pattern and outcome in children with haemolytic-uraemic syndrome and neurological impairment treated with eculizumab. Dev Med Child Neurol 55:758-765. https://doi.org/10.1111/dmcn.12161

14. Matthies J, Hünseler C, Ehren R, et al (2016) Extrarenal Manifestations in Shigatoxin-associated Haemolytic Uremic Syndrome. Klin Padiatr 228:181-188. https://doi.org/10.1055/s-0042-108444

15. Loos S, Aulbert W, Hoppe B, et al (2017) Intermediate follow-up of pediatric patients with hemolytic uremic syndrome during the 2011 outbreak caused by E. Coli 0104:H4. Clin Infect Dis 64:16371643. https://doi.org/10.1093/cid/cix218

16. Tavasoli A, Zafaranloo N, Hoseini R, et al (2019) Chronic neurological complications in hemolytic uremic syndrome in children. Iran J Kidney Dis 13:32-35

17. Giordano M, Baldassarre ME, Palmieri V, et al (2019) Management of stec gastroenteritis: Is there a role for probiotics? Int. J. Environ. Res. Public Health 16

18. Ylinen E, Salmenlinna S, Halkilahti J, et al (2020) Hemolytic uremic syndrome caused by Shiga toxin-producing Escherichia coli in children: incidence, risk factors, and clinical outcome. Pediatr Nephrol. https://doi.org/10.1007/s00467-020-04560-0

19. Steinborn M, Leiz S, Rüdisser K, et al (2004) CT and MRI in haemolytic uraemic syndrome with central nervous system involvement: distribution of lesions and prognostic value of imaging 
findings. Pediatr Radiol 34:805-810. https://doi.org/10.1007/s00247-004-1289-2

20. Brown CC, Garcia X, Bhakta RT, et al (2021) Severe Acute Neurologic Involvement in Children With Hemolytic-Uremic Syndrome. Pediatrics 147:e2020013631. https://doi.org/10.1542/peds.2020013631

21. Martin DL, MacDonald KL, White KE, et al (1990) The epidemiology and clinical aspects of the hemolytic uremic syndrome in Minnesota. N Engl J Med 323:1161-1167. https://doi.org/10.1056/NEJM199010253231703

22. Bale JFJ, Brasher C, Siegler RL (1980) CNS manifestations of the hemolytic-uremic syndrome. Relationship to metabolic alterations and prognosis. Am J Dis Child 134:869-872. https://doi.org/10.1001/archpedi.1980.02130210053014

23. Sheth KJ, Swick HM, Haworth N (1986) Neurological involvement in hemolytic-uremic syndrome. Ann Neurol 19:90-93. https://doi.org/10.1002/ana.410190120

24. Hahn JS, Havens PL, Higgins JJ, et al (1989) Neurological Complications of Hemolytic-Uremic Syndrome. J Child Neurol 4:108-113. https://doi.org/10.1177/088307388900400206

25. Cimolai N, Morrison BJ, Carter JE (1992) Risk factors for the central nervous system manifestations of gastroenteritis-associated hemolytic-uremic syndrome. Pediatrics 90:616-621

26. Siegler RL (1994) Spectrum of extrarenal involvement in postdiarrheal hemolytic-uremic syndrome. J Pediatr 125:511-518. https://doi.org/10.1016/s0022-3476(94)70001-x

27. Banatvala N, Griffin PM, Greene KD, et al (2001) The United States national prospective hemolytic uremic syndrome study: Microbiologic, serologic, clinical, and epidemiologic findings. J Infect Dis 183:1063-1070. https://doi.org/10.1086/319269

28. Gerber A, Karch H, Allerberger F, et al (2002) Clinical course and the role of Shiga toxin-producing Escherichia coli infection in the hemolytic-uremic syndrome in pediatric patients, 1997-2000, in Germany and Austria: A prospective study. J Infect Dis 186:493-500. https://doi.org/10.1086/341940

29. Loos S, Ahlenstiel T, Kranz B, et al (2012) An outbreak of shiga toxin-producing escherichia coli 0104:H4 hemolytic uremic syndrome in Germany: Presentation and short-term outcome in children. Clin Infect Dis 55:753-759. https://doi.org/10.1093/cid/cis531

30. Siegler RL, Pavia AT, Christofferson RD, Milligan MK (1994) A 20-year population-based study of postdiarrheal hemolytic uremic syndrome in Utah. Pediatrics 94:35-40

31. Eriksson KJ, Boyd SG, Tasker RC (2001) Acute neurology and neurophysiology of haemolyticuraemic syndrome. Arch Dis Child 84:434-435. https://doi.org/10.1136/adc.84.5.434

32. Clarke SLN, Sen ES, Ramanan A V. (2016) Juvenile idiopathic arthritis-associated uveitis. Pediatr. Rheumatol. 14

33. Nathanson S, Kwon T, Elmaleh M, et al (2010) Acute neurological involvement in diarrhea-associated hemolytic uremic syndrome. Clin J Am Soc Nephrol 5:1218-1228.

https://doi.org/10.2215/CJN.08921209

Page $11 / 19$ 
34. Pape L, Hartmann H, Bange FC hristop., et al (2015) Eculizumab in Typical Hemolytic Uremic Syndrome (HUS) With Neurological Involvement. Medicine (Baltimore) 94:e1000. https://doi.org/10.1097/MD.0000000000001000

35. Giordano P, Netti GS, Santangelo L, et al (2019) A pediatric neurologic assessment score may drive the eculizumab-based treatment of Escherichia coli-related hemolytic uremic syndrome with neurological involvement. Pediatr Nephrol 34:517-527. https://doi.org/10.1007/s00467-018-4112-2

36. Khalid M, Andreoli S (2019) Extrarenal manifestations of the hemolytic uremic syndrome associated with Shiga toxin-producing Escherichia coli (STEC HUS). Pediatr Nephrol 34:2495-2507. https://doi.org/10.1007/s00467-018-4105-1

37. Dundas S, Murphy J, Soutar RL, et al (1999) Effectiveness of therapeutic plasma exchange in the 1996 Lanarkshire Escherichia cell 0157:H7 outbreak. Lancet 354:1327-1330. https://doi.org/10.1016/S0140-6736(99)01251-9

38. Colic E, Dieperink H, Titlestad K, Tepel M (2011) Management of an acute outbreak of diarrhoeaassociated haemolytic uraemic syndrome with early plasma exchange in adults from southern Denmark: An observational study. Lancet 378:1089-1093. https://doi.org/10.1016/S01406736(11)61145-8

39. Kielstein JT, Beutel G, Fleig S, et al (2012) Best supportive care and therapeutic plasma exchange with or without eculizumab in Shiga-toxin-producing E. coli 0104:H4 induced haemolytic-uraemic syndrome: An analysis of the German STEC-HUS registry. Nephrol Dial Transplant 27:3807-3815. https://doi.org/10.1093/ndt/gfs394

40. Menne J, Nitschke M, Stingele R, et al (2012) Validation of treatment strategies for enterohaemorrhagic Escherichia coli 0104:H4 induced haemolytic uraemic syndrome: Case-control study. BMJ 345:e4565. https://doi.org/10.1136/bmj.e4565

41. Gianviti A, Perna A, Caringella A, et al (1993) Plasma Exchange in Children With Hemolytic-Uremic Syndrome at Risk of Poor Outcome. Am J Kidney Dis 22:264-266. https://doi.org/10.1016/S02726386(12)70316-5

42. Percheron L, Gramada R, Tellier S, et al (2018) Eculizumab treatment in severe pediatric STEC-HUS: a multicenter retrospective study. Pediatr Nephrol 33:1385-1394. https://doi.org/10.1007/s00467-0183903-9

43. Lapeyraque A-L, Malina M, Fremeaux-Bacchi V, et al (2011) Eculizumab in Severe Shiga-ToxinAssociated HUS. N Engl J Med 364:2561-2563. https://doi.org/10.1056/nejmc1100859

44. Fivush BA, Jabs K, Neu AM, et al (1998) Chronic renal insufficiency in children and adolescents: The 1996 annual report of NAPRTCS. Pediatr Nephrol 12:328-337.

https://doi.org/10.1007/s004670050462

45. Fiser DH, Tilford JM, Roberson PK (2000) Relationship of illness severity and length of stay to functional outcomes in the pediatric intensive care unit: A multi-institutional study. Crit Care Med 28:1173-1179. https://doi.org/10.1097/00003246-200004000-00043 
46. Bauer A, Loos S, Wehrmann C, et al (2014) Neurological involvement in children with E. coli 0104:H4induced hemolytic uremic syndrome. Pediatr Nephrol 29:1607-1615.

https://doi.org/10.1007/s00467-014-2803-x

47. Keenswijk W, Raes A, De Clerck M, Vande Walle J (2019) Is Plasma Exchange Efficacious in Shiga Toxin-Associated Hemolytic Uremic Syndrome? A Narrative Review of Current Evidence. Ther Apher Dial 23:118-125. https://doi.org/10.1111/1744-9987.12768

48. Walsh PR, Johnson S (2019) Eculizumab in the treatment of Shiga toxin haemolytic uraemic syndrome. Pediatr. Nephrol. 34:1485-1492

49. Keenswijk W, Raes A, Vande Walle J (2018) Is eculizumab efficacious in Shigatoxin-associated hemolytic uremic syndrome? A narrative review of current evidence. Eur. J. Pediatr. 177:311-318

50. Schwartz J, Padmanabhan A, Aqui N, et al (2016) Guidelines on the Use of Therapeutic Apheresis in Clinical Practice-Evidence-Based Approach from the Writing Committee of the American Society for Apheresis: The Seventh Special Issue. J. Clin. Apher. 31:149-162

51. Ağbaş A, Göknar N, Akıncı N, et al (2018) Outbreak of Shiga toxin-producing Escherichia-coliassociated hemolytic uremic syndrome in Istanbul in 2015: outcome and experience with eculizumab. Pediatr Nephrol 33:2371-2381. https://doi.org/10.1007/s00467-018-4033-0

52. Monet-Didailler C, Chevallier A, Godron-Dubrasquet A, et al (2021) Outcome of children with Shiga toxin-associated haemolytic uraemic syndrome treated with eculizumab: a matched cohort study. Nephrol Dial Transplant 35:2147-2153. https://doi.org/10.1093/NDT/GFZ158

53. Delmas Y, Vendrely B, Clouzeau B, et al (2014) Outbreak of Escherichia coli 0104:H4 haemolytic uraemic syndrome in France: Outcome with eculizumab. Nephrol Dial Transplant 29:565-572. https://doi.org/10.1093/ndt/gft470

54. Garg AX, Suri RS, Barrowman N, et al (2003) Long-term Renal Prognosis of Diarrhea-Associated Hemolytic Uremic Syndrome: A Systematic Review, Meta-analysis, and Meta-regression. J. Am. Med. Assoc. 290:1360-1370

55. Roche A, Poo P, Maristany M, et al (2011) Haemolytic-Uraemic Syndrome: Neurologic Symptoms, Neuroimaging and Neurocognitive Outcome. Neuroimaging Clin - Comb Res Pract. https://doi.org/10.5772/23649

56. Schlieper A, Orrbine E, Wells GA, et al (1999) Neuropsychological sequelae of haemolytic uraemic syndrome. Arch Dis Child 80:214-220. https://doi.org/10.1136/adc.80.3.214

\section{Tables}

Table 1. Demographics, Clinical Presentation and Management of pediatric HUS patients 
Total HUS

Group

$\mathrm{n}=202$
HUS

Neurological Group

$\mathrm{n}=22$
HUS Non -Neurological Group $\mathrm{n}=180$

graphics

»r, Female: Male, $\mathrm{n}$

114: 88

$13: 9$

$101: 79$ .79

rears) median

$3.2(1.6-6.3)$

$2.6(1.1-7.4)$

$3.2(1.6-6.2)$

.44

ategory, n (\%)

rear

2 years

$15(7.4)$

4 (18.2)

$11(6.1)$

$44(21.8)$

4 (18.2)

$40(22.2)$

.228

j years

79 (39.1)

7 (31.8)

$72(40.0)$

64 (31.7)

7 (31.8)

57 (31.7)

n, n (\%)

ring

35 (17.3)

4 (18.2)

31 (17.2)

$86(42.6)$

$12(54.5)$

74 (41.1)

$6(27.3)$

$58(32.2)$

$17(8.4)$

$0(0.0)$

$17(9.4)$

lays

n (IQR)

$10.0(6.0-16.0)$

$21.0(13.0-34.0)$

$9.0(6.0-15.0)$

$<0.001$

dmission, n (\%)

48 (23.8)

19 (86.4)

29 (16.1)

$<0.001$

\section{ating symptoms}

ation period, days

n (IQR)

5 (4-7)

$5.0(3.5-7.0)$

$5(4.0-7.0)$

.092

ıea, n (\%)

196 (97)

$22(100)$

174 (96.7)

0.39

Output, n (\%)

rmal

45 (22.3)

$1(4.5)$

157 (77.7)

$21(95.5)$

$44(24.4)$

136 (75.6)

.034

\section{atory Findings}

ssion) median (IQR)

cell count (x10^9/l)

ophils (x10^9/1)

globin $(\mathrm{g} / \mathrm{L})$

ets $\left(\mathrm{x} 10^{\wedge} 9 / \mathrm{l}\right)$

(mmol/L)

nine $(\mu \mathrm{mol} / \mathrm{L})$

'reatinine $(\mu \mathrm{mol} / \mathrm{L})$

$\mathrm{m}(\mathrm{mmol} / \mathrm{L})$

$\begin{array}{cc}13.2(10.4-18.4) & 16.1(12.0-20.0) \\ 7.0(5.1-11.1) & 7.4(5.3-12.2) \\ 87.0(75.0- & 87.5(76.8-98.5) \\ 100.0) & 51.5(29.8-63.5) \\ 51.0(31.0-76.0) & 24.6(16.1-37.1) \\ 23.4(15.2-32.1) & 297.5(148.5- \\ 211(121.5-314.5) & 371.3)\end{array}$

349.5 (150.5-578.8) 383 (271.5 - 737.5)

$134.0(132.0-136.0) \quad 135(132.0-138.0)$

$\begin{array}{cc}13.0(10.4-18.1) & .18 \\ 6.8(5.1-11.0) & .18 \\ 87.0(74.3-100.8) & .80 \\ 50.0(31.0-78.0) & .82 \\ 23.3(15.1-32.0) & .63 \\ 208(120.0-305.0) & .06 \\ 349.0(142.0- & .82 \\ 576.0) & .34 \\ 134.0(132.0-136.0) & \\ & \\ 88(48.9) & <.001 \\ 10(5.6) & \\ 73(40.6) & .016 \\ 5(2.8) & \\ 9.0(6.0-13.0) & .81 \\ 9(5.0) & <.001 \\ 4.0(1.0-5.0) & 0.503 \\ 0(0) & <.001\end{array}$

nent

is, $\mathrm{n}(\%)$

$107(53.0)$

$19(86.4)$

$16(7.9)$

$6(27.3)$

$83(41.1)$

$10(45.5)$

$8(4.0)$

$3(13.6)$

$9.0(6.0-13.0)$

$11.0(7.3-19.0)$

ion, days, (IQR)

$24(11.9) \quad 15(68.2)$

ion, days, median (IQR)

$4(2.5-5)$

$4.0(3.0-5.0)$

$8(4.0)$

$8(36.4)$

$0(0)$

$<.001$

viations: CVVH, continuous veno-venous hemofiltration; HUS, hemolytic uremic syndrome; ICU, Intensive care $\mathrm{QR}$, interquartile range; LOS, Length of stay; $\mathrm{n}$, number; PD; peritoneal dialysis; PE, plasma exchange 
Table 2. E.coli serogroups identified from pediatric HUS patients

\begin{tabular}{|c|c|c|c|c|c|c|c|}
\hline chia Coli & $\begin{array}{l}\text { Total HUS } \\
\text { Group } \\
\mathrm{n}=202(\%)\end{array}$ & $\begin{array}{c}\text { stx detected } \\
\mathrm{n}(\%)\end{array}$ & $\begin{array}{l}\text { Neurological Group } \\
\quad \mathrm{n}=21\end{array}$ & $\begin{array}{c}\text { stx detected } \\
\mathrm{n}(\%)\end{array}$ & $\begin{array}{c}\text { Non -Neurological } \\
\text { Group } \\
\mathrm{n}=181(\%)\end{array}$ & $\begin{array}{c}\text { stx detected } \\
\mathrm{n}(\%)\end{array}$ & $\begin{array}{c}\mathrm{P}^{*} \\
\text { value }\end{array}$ \\
\hline .7, n (\%) & $101(50)$ & $86(85)$ & 7 (28.6) & $5(66)$ & $94(52)$ & $81(86)$ & 0.05 \\
\hline i, n (\%) & $62(30)$ & 53 (85) & $8(38.0)$ & $6(75)$ & $54(29.8)$ & 47 (87) & 0.34 \\
\hline sle, n (\%) & 16 (79) & $12(75)$ & $4(19)$ & $3(75)$ & $12(6.6)$ & $9(75)$ & 0.05 \\
\hline $5, \mathrm{n}(\%)$ & $13(6.4)$ & $12(92)$ & $2(9.5)$ & $2(100)$ & $11(6)$ & 10 (83) & 0.20 \\
\hline I3, n (\%) & $4(2.0)$ & $4(100)$ & 0 & 0 & $4(2.2)$ & $4(100)$ & 0.49 \\
\hline only, n (\%) & $4(1.5)$ & $4(1.5)$ & 0 & 0 & $4(2.2)$ & $4(2.2)$ & 0.49 \\
\hline $1, \mathrm{n}(\%)$ & $3(1.5)$ & $3(100)$ & $1(4.8)$ & $1(100)$ & $2(1.1)$ & $2(100)$ & 0.19 \\
\hline $2, \mathrm{n}(\%)$ & $1(0.5)$ & $1(100)$ & 0 & - & $1(0.6)$ & $1(100)$ & 0.73 \\
\hline \multirow[t]{2}{*}{ i, n (\%) } & $1(0.5)$ & $1(100)$ & 0 & - & $1(0.5)$ & $1(100)$ & 0.80 \\
\hline & $205^{* *}$ & $176^{* *}(85)$ & 21 & $16(76)$ & $184 * *$ & $160^{* *}(86)$ & - \\
\hline
\end{tabular}

Legend: HUS, hemolytic uremic syndrome; PCR, polymerase chain reaction; stx, shigaotoxin

*difference in serotypes between neurological and non-neurological group

**3 patients had both $\mathrm{O} 26 \& 0157$ 
Acute Radiological Features of HUS

CT

MRI
Neurological

Outcome

(PCPC

Score)

\begin{tabular}{|c|c|c|c|c|c|c|c|}
\hline No. & CNS Symptoms & & & EEG & Treatment & AEDs & Score) \\
\hline \multirow[t]{4}{*}{1} & Encephalopathic & - & RD and T2-hyperintensity & - & $\mathrm{PE}$ & BZD & Normal (1) \\
\hline & GTCS & & in the centrum semi-ovale & & & Discharge: Nil & \\
\hline & & & $\&$ PVWM & & & & \\
\hline & & & Follow-Up: Resolved & & & & \\
\hline \multirow[t]{3}{*}{2} & Encephalopathic & - & - & Absence of & PE then & - & Deceased \\
\hline & Hypotonic & & & cerebral & Eculizumab & & \\
\hline & & & & activity & & & \\
\hline 3 & Encephalopathic & - & - & - & Eculizumab & - & Normal (1) \\
\hline \multirow[t]{2}{*}{4} & GTCS & - & - & - & - & BZD & Baseline (2) \\
\hline & & & & & & Discharge: Nil & \\
\hline \multirow[t]{2}{*}{5} & Status Epilepticus & No & - & - & $\mathrm{PE}$ & BZD, PHY & Normal (1) \\
\hline & & & & & & Discharge: Nil & \\
\hline \multirow[t]{2}{*}{6} & Seizure & No & No & Slow & $\mathrm{PE}$ & VPA & Baseline (2) \\
\hline & & & & & & Discharge: VPA & \\
\hline \multirow[t]{4}{*}{7} & Encephalopathic & No & No & Slow & Eculizumab & BZD, PHY, & Normal (1) \\
\hline & GTCS then prolonged & & & & & LEV & \\
\hline & focal seizure later in & & & & & Discharge: LEV & \\
\hline & admission & & & & & & \\
\hline \multirow[t]{2}{*}{8} & GTCS & - & & - & Eculizumab & PHY & Normal (1) \\
\hline & & & & & & Discharge: Nil & \\
\hline \multirow[t]{2}{*}{9} & Encephalopathic & - & No & - & $\mathrm{PE}$ & BZD & Normal (1) \\
\hline & GTCS & & & & & Discharge: Nil & \\
\hline 10 & GTCS & No & No & Slow & Eculizumab & - & Normal (1) \\
\hline \multirow[t]{2}{*}{11} & Encephalopathic & - & No & - & $\mathrm{PE}$ & BZD, PHB, PHY & Normal (1) \\
\hline & Status Epilepticus & & & & & Discharge: Nil & \\
\hline \multirow[t]{2}{*}{12} & GTCS & No & - & - & $\mathrm{PE}$ & BZD & Normal (1) \\
\hline & & & & & & Discharge: Nil & \\
\hline 13 & Encephalopathic & No & - & Slow & $\mathrm{PE}$ & - & Normal (1) \\
\hline \multirow[t]{4}{*}{14} & Status Epilepticus & Low attenuation in & T2 hyperintensity \& & - & PE then & PHB, PHY, THI & Normal (1) \\
\hline & Focal Seizures & bilateral BG \& & mixed increased/RD in & & Eculizumab & Discharge: $\mathrm{PHY}$ & \\
\hline & & THAL & BG \& THAL & & & & \\
\hline & & & Follow-Up: Improved & & & & \\
\hline \multirow[t]{4}{*}{15} & Encephalopathic & Loss of GWM & T2 and FLAIR & Abnormal & $\mathrm{PE}$ & PHB, PHY & Normal (1) \\
\hline & Hemiparesis & differentiation in $\mathrm{R}$ & hyperintensity in the & & & Discharge: РНВ & \\
\hline & GTCS & occipital lobe & PVWM bilaterally $(\mathrm{R}>\mathrm{L})$ & & & & \\
\hline & & & $\&$ R occipital lobe & & & & \\
\hline \multirow[t]{7}{*}{16} & Prolonged focal motor & Low attenuation in & T2 hyperintensity \& & Slow & Eculizumab & BZD & Mild \\
\hline & seizure & bilateral BG \& & mixed increased/RD in & & then PE & Discharge: Nil & Impairment \\
\hline & Encephalopathic & THAL & BG \& THAL & & & & (2) \\
\hline & Abnormal tone & & & & & & Difficulty \\
\hline & & & & & & & with \\
\hline & & & & & & & complex \\
\hline & & & & & & & motor tasks \\
\hline \multirow[t]{2}{*}{17} & Encephalopathic & - & - & Slow & $\mathrm{PE}$ & LEV & Normal (1) \\
\hline & & & & & & Discharge: Nil & \\
\hline \multirow[t]{2}{*}{18} & Status epilepticus & - & $\mathrm{RD}$ in $\mathrm{WM} \& \mathrm{BG}$ & Slow & PE then & BZD, РHB & Normal (1) \\
\hline & & & Follow-Up: Resolved & & Eculizumab & Discharge: Nil & \\
\hline
\end{tabular}




\begin{tabular}{|c|c|c|c|c|c|c|c|}
\hline 20 & Focal motor seizure & - & $\begin{array}{c}\text { RD in centrum semi-ovale } \\
\text { \& PVWM } \\
\text { T2 hyperintensity in } \\
\text { centrum semi-ovale }\end{array}$ & Slow & $\mathrm{PE}$ & $\begin{array}{c}\text { BZD, LEV } \\
\text { Discharge: Nil }\end{array}$ & Normal (1) \\
\hline 21 & $\begin{array}{c}\text { Left } 4^{\text {th }} \mathrm{CN} \text { palsy } \\
\text { L upper limb } \\
\text { weakness }\end{array}$ & No & $\begin{array}{l}\text { Increased DWI \& edema } \\
\text { in cerebellum }\end{array}$ & - & $\mathrm{PE}$ & - & Normal (1) \\
\hline 22 & GTCS & No & - & - & - & $\begin{array}{c}\text { BZD } \\
\text { Discharge: Nil }\end{array}$ & Normal (1) \\
\hline
\end{tabular}

Abbreviations: AED, antiepileptic drugs; BG, basal ganglia; BZD, benzodiazepine; CN, cranial nerve; CNS, central nervous system; CT, computed tomography; DWI, diffusion-weighted imaging; EEG, electroencephalogram; GTCS, generalized tonic-clonic seizure; L, left; LEV, levetiracetam; MRI, magnetic resonance imaging; PCPC, Pediatric Cerebral Performance Category PE, plasma exchange; PHB, phenobarbitone; PHY, phenytoin; PVWM, periventricular white matter; $\mathrm{R}$, right; $\mathrm{RD}$, restricted diffusion

Table 4: Renal outcome of the total group with STEC-HUS

\begin{tabular}{|c|c|c|c|c|}
\hline $\begin{array}{l}\text { Total Group } \\
n=202(\%)\end{array}$ & $\begin{array}{c}\text { Neurological } \\
\text { Group } \\
\mathrm{n}=22(\%)\end{array}$ & $\begin{array}{c}\text { Non-Neurological } \\
\text { Group } \\
n=180(\%)\end{array}$ & $\begin{array}{c}P \\
\text { value }\end{array}$ & \\
\hline Long-term data available & 178 (88.1) & 21 (95.5) & $157(87.2)$ & \\
\hline Regional center follow-up & $18(8.9)$ & 0 & $18(10.0)$ & .11 \\
\hline Lost to follow-up & $5(2.5)$ & 0 & $5(2.8)$ & \\
\hline \multirow[t]{2}{*}{ Deceased } & $1(0.5)$ & $1(4.5)$ & 0 & \\
\hline & $\begin{array}{c}\text { Total Group } \\
\mathrm{n}=178 \text { (\%) }\end{array}$ & $\begin{array}{c}\text { Neurological } \\
\text { Group } \\
n=21 \text { (\%) }\end{array}$ & $\begin{array}{c}\text { Non- } \\
\text { Neurological } \\
\text { Group } \\
\mathrm{n}=157(\%)\end{array}$ & \\
\hline Duration of follow-up, years median (IQR) & $2.4(0.7-5.5)$ & $3.6(2.3-4.6)$ & $2.2(0.6-5.6)$ & .037 \\
\hline Complete renal recovery & $154(86.5)$ & $15(71.4)$ & $139(88.5)$ & .031 \\
\hline Long-term renal sequelae & $24(13.5)$ & $6(26.6)$ & $18(11.5)$ & .031 \\
\hline Proteinuria & $14(7.9)$ & $5(23.8)$ & $9(5.7)$ & .004 \\
\hline Hypertension & $7(3.9)$ & $1(4.8)$ & $5(3.2)$ & .707 \\
\hline $\begin{array}{l}\text { Mild impairment } \\
\left.\min / 1.73 \mathrm{~m}^{2}\right)\end{array}$ & $6(3.4)$ & $3(14.3)$ & $3(1.9)$ & .003 \\
\hline $\begin{array}{l}\text { Mild/Moderate impairment } \\
\left(\text { eGFR } 45-59 \mathrm{ml} / \mathrm{min} / 1.73 \mathrm{~m}^{2}\right)\end{array}$ & $4(2.2)$ & $0(0.0)$ & $4(2.5)$ & .459 \\
\hline CKD 5-Transplant & $2(1.1)$ & $1(4.8)$ & $1(0.6)$ & `.092 \\
\hline
\end{tabular}

Abbreviations: eGFR, estimated glomerular filtration rate; CKD, Chronic Kidney Disease; NS, not significant 
Complete renal recovery: Absence of proteinuria or hypertension and a normal eGFR,

Hypertension: $\geq 95^{\text {th }}$ percentile for age, height and sex and requiring an antihypertensive medication

Proteinuria: $>0.15 \mathrm{~g} / \mathrm{L}$ or urinary protein-to-creatinine ratio greater than $20 \mathrm{mg} / \mathrm{mmol}$

\section{Figures}

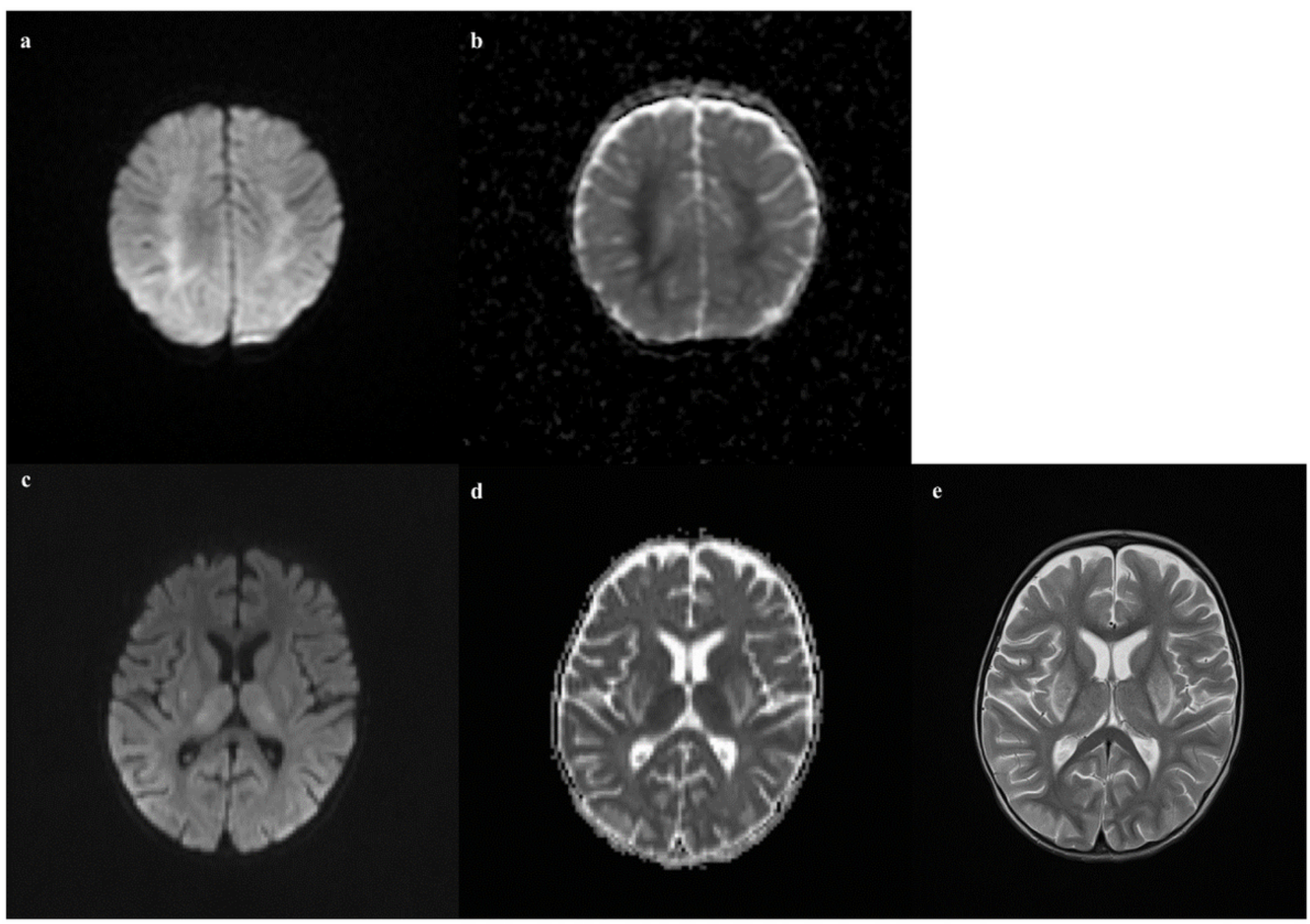

\section{Figure 1}

a \& 1b (Patient 1): Axial DWI (a) and ADC map (b) shows reduced diffusivity in both centrum semi-ovale which extended inferiorly to the periventricular white matter adjacent to bilateral frontal horns. 1c - e (Patient 16): Axial DWI (c) and ADC map (d) show restricted diffusion in the thalami bilaterally with increased diffusion within the periphery of the lentiform nuclei. There is corresponding increased signal abnormality in grey matter structures on axial T2 images (e)

\section{Supplementary Files}

This is a list of supplementary files associated with this preprint. Click to download. 
- SupplementaryFigure1Revised.jpeg

- SupplementaryTable1.docx

- SupplementaryTable2.docx 